\title{
ANALISIS PERBANDINGAN PRODUKTIVITAS PRODUKSI BETON READYMIX METODE WETMIX DAN DRYMIX
}

\author{
Sunarto Suryanto ${ }^{1}$, Sugiharti ${ }^{2}$, Fauzi Akbar R. ${ }^{3}$ \\ ${ }^{1,2,3}$ Dosen Jurusan Teknik Sipil Politeknik Negeri Malang \\ 1'nartosuryanto@gmail.com, ${ }^{2}$ sugiharti@polinema.ac.id, ${ }^{3}$ fauziakbar@polinema.ac.id
}

(Artikel diterima: Februari 2020, direvisi: April 2020, diterima untuk terbit: Juli 2020)

\begin{abstract}
Abstrak - Terdapat dua metode produksi beton readymix yang digunakan saat ini yaitu wetmix dan drymix. Pencampuran wetmix merupakan metode pencampuran beton yang memiliki produktivitas yang lebih tinggi dibandingkan drymix. Tingginya produktivitas tipe wetmix dikarenakan pan pengaduk pada pencampuran wetmix memiliki putaran mixing yang lebih cepat dari pada tipe drymix sehingga durasi pengadukan lebih cepat. Adapun perbaikan yang dapat dilakukan untuk meningkatkan produktivitas produksi beton readymix adalah dengan merubah bentuk batching plant serta memperbesar kapasitas hooper agregat agar dapat mengurangi waktu tunggu alat lain pada operasi penggunaan loader, sebab produksi beton pada aktivitas produksi berasal dari penggunaan loader untuk transportasi agregat.
\end{abstract}

Kata kunci: Wetmix, Drymix, Produktivitas.

\section{Pendahuluan}

Saat ini terdapat dua metode pencampuran yang berbeda pada produksi beton di batching plant. Metode pencampuran tersebut dapat dikategorikan menjadi dua jenis yaitu wetmix dan drymix. Pencampuran wetmix merupakan proses produksi beton dimana agregat, semen, air, dan zat adiktif yang di aduk dalam pan pengaduk. Sedangkan pencampuran drymix merupakan pencampuran material penyusun beton yang dilakukan di dalam truck mixer. Kedua jenis batchingplant tersebut yang saat ini ada di pasaran dan sering digunakan oleh perusahaan readymix.

Dengan melihat fakta bahwa adanya perbedaan dalam proses produksi tersebut, maka penulis akan melakukan Analisis Perbandingan Produktivitas Produksi Beton Readymix Metode Wetmix dan Drymix. Pada penelitian ini dilakukan dengan mengunjungi batchingplant dengan jenis Wetmix dan Drymix untuk selanjutnya merekam proses produksi beton. Hasil rekaman digunakan sebagai alat bantu dalam merumuskan waktu siklus produksi masing-masing alat. Data yang didapat kemudian disimulasikan untuk mendapatkan produktivitas dari produksi beton wetmix dan drymix tersebut.

Penelitian ini merumuskan beberapa masalah anatra lain, perbandingan produksi beton readymix dengan metode wetmix dan drymix 2, apa saja proses produksi yang menghambat kecepatan produksi beton readymix, dan bagaimana upaya perbaikan yang dapat dilakukan agar proses produksi beton dapat berjalan lebih cepat. Selain itu untuk memfokuskan arah penelitian, maka terdapat beberapa batasan masalah yaitu pengamatan dilakukan pada batchingplant yang berada di daerah jawa timur, penelitian tidak meninjau mutu yang dihasilkan setelah proses pengadukan baik dari aspek slump, setting time, maupun strength, penelitian ditinjau dalam satu mutu beton yang sama namun dengan proses produksi yang berbeda, tidak membahas secara khusus proses kimia yang terjadi pada campuran beton, dan penelitian tidak meninjau aspek biaya yang mempengaruhi pemilihan metoda pencampuran wetmix dan drymix.

\section{DASAR TEORI}

\section{A. Material Penyusun Beton Readymix}

Pada dasarnya material bahan baku untuk beton readymix sama dengan beton yang diproduksi secara tradisional di lokasi proyek, namun pada beton readymix lebih umum menggunakan bahan tambahan seperti admixture karena adanya proses transportasi dari batching plant menuju lokasi proyek untuk menyesuaikan waktu setting beton. Secara keseluruhan material penyusun beton readymix anatara lain:

- Semen

- Agregat

- Air

- Bahan Tambah

\section{B. Pencampuran Wetmix}

Pada proses produksi beton dengan pencampuran wetmix, proses dimulai dari pengangkutan material dari lokasi stock pile menuju loading bin dengan menggunakan wheel loader selanjutnya material (aggregate) di timbang dan dimasukan kedalam mixer dengan kapasitas $3 \mathrm{~m}^{3}$ dengan bantuan belt conveyor dan dilakukan pencampuran dengan semen dan air. Alat pengaduk membutuhkan beberapa saat untuk menjadikan semua material tersebut menjadi beton. Setelah selesai selanjutnya beton dituangkan ke dalam truck mixer. Proses pencamputran berlangsung 2 kali agar dapat memenuhi truck mixer untuk selanjutnya dibawa menuju lokasi pengecoran.

\section{Pencampuran Drymix}

Pembuat beton dengan sistem adukan kering atau drymix, merupakan proses pembuatan beton readymix dimana material yang berupa pasir, batu, air dan semen diaduk dan dijadikan beton di dalam truck mixer. Batching plant hanya berfungsi untuk menimbang material dan menghantarkannya ke dalam drum truck mixer. Semua material yg telah masuk ke dalam drum mixer akan diaduk beberapa saat dengan putaran drum 
yang sudah ditentukan untuk dijadikan beton.

\section{Pemodelan Cyclone}

Cyclone (Cyclic Operation Network) merupakan suatu teknik pemodelan yang dirancang dalam penggunaan analisa suatu kegiatan konstruksi dalam satu simulasi yang kontinyu pada lapangan. Pemodelan dengan menggunakan proses cyclone ini menggunakan software yang disebut microcyclone dimana melibatkan tugas-tugas (tasks), diperoleh durasi setiap task yang ada uraian suatu kegiatan yang disebut work task.

Enam elemen dalam pemodelan cyclone pada umumnya digambarkan dalam bentuk beberapa simbol yang sering digunakan. Adapun tabel bentuk elemen yang sering digunakan dapat dilihat pada Tabel 1.

Tabel 1. Elemen - elemen dalam pemodelan cyclone

\begin{tabular}{|c|c|c|}
\hline Nama & Simbol & Fungsi \\
\hline $\begin{array}{l}\text { Combination } \\
\text { (COMBI) } \\
\text { Activity }\end{array}$ & P & $\begin{array}{l}\text { Elemen yang akan menjadi aktif setelah beberapa kondisi } \\
\text { terpenuhi, misalnya tersedianya beberapa jenis sumberdaya } \\
\text { tertentu untuk memulai pekerjaan }\end{array}$ \\
\hline Normal Activity & & $\begin{array}{l}\text { Elemen yang akan aktif setelah kegiatan lain yang mendahuluinya } \\
\text { selesai. Normal hanya dapat di dahului oleh normal atau combi } \\
\text { lainnya dan tidak dapat didahului oleh queue }\end{array}$ \\
\hline Queue Node & & $\begin{array}{l}\text { Berperan sebagai "ruang tunggu" sementara bagi sumberdaya } \\
\text { ketika sedang tidak aktif atau sedang dalam posisi menunggu }\end{array}$ \\
\hline Function Node & & $\begin{array}{l}\text { Tidak mempunyai fungsi intrinsik tetapi dapat disisipkan di mana } \\
\text { saja kecuali diantara simbul combi \& queue yang mendahului, } \\
\text { untuk membentuk fungsi khusus tertentu }\end{array}$ \\
\hline Accumulator & & $\begin{array}{l}\text { Merupakan sistem pemantauan \& pengendalian bagi elemen- } \\
\text { elemen cyclone lainnya }\end{array}$ \\
\hline Arc & & $\begin{array}{l}\text { Berfungsi menunjukkan arah aliran sumberdaya antara sumberdaya } \\
\text { dan work task }\end{array}$ \\
\hline
\end{tabular}

Pada pemodelan Cyclone semua resources dan tasks secera ekspilisit sebagai flow unit, adapun prosedur pemodelan dapat dilihat sebagai berikut :

- Identifikasi resources dan flow units

- Mengembangkan siklus dari flow units

- Mengintgrasikan siklus dari flow units

- Inisial flow units

\section{E. Pemodelan Durasi}

Dalam menghubungkan waktu perpindahan pelaksanaan suatu tugas, maka pada model Cyclone ini bisa memberikan periode waktu suatu unit resource terlibat dalam tugasnya dengan urutan tertentu. Dengan begitu maka model bisa menentukan output operasional dan tingkat produktifitas dalam satuan waktu. Sehingga memungkinkan untuk menentukan waktu idle suatu resources dengan jumlah yang berbeda, yang berpengaruh pada tingkat produktifitas.
Dua dari elemen sistem Cyclone bisa digunakan untuk menentukan lama penundaan atau waktu perpindahan dari tugas yang berbeda. Sistem kinerjanya adalah fungsi dalam menentukan elemen waktu dan logika sistemnya. Dalam mendefinisikan tugas Combi dan Normal dan hubungannya dengan waktu adalah penting untuk memberikan gambaran penting dalam keadaan sebenarnya.

\section{Durasi deterministik}

Durasi waktu yang bisa pasti ditentukan merupakan durasi waktu pasti. Hal ini bisa terjadi karena, resource yang digunakan memberikan nilai pasti dalam setiap arus yang diperhitungkan dan durasi tugas memiliki variasi waktu yang kecil sehingga lebih baik dianggap sebagai waktu yang konstan.

\section{Durasi acak (random)}

Didalam sistem, keacakan lama (durasi) tugas-tugas yang mempengaruhi satu siklus dipertimbangkan. Pengaruh keacakan durasi dalam perpindahan unit flow 
sangat penting menyebabkan perubahan yang disebabkan oleh penundaan dalam siklus produktifitas dan operasi. Durasi acak (random) ini terdiri dari normal, lognormal, beta, gamma, eksponential, Chi - Square, pareto, dan lain - lain.

\section{F. Simulasi}

Simulasi merupakan penggunaan model rencana dalam melakukan percobaan - percobaan untuk mendapatkan kemungkinan - kemungkinan dari model rencana tersebut. Simulasi ini digunakan untuk mencari durasi steady state tiap work task sehingga dapat digunakan untuk mengidentifikasi durasi pemakaian alat yang terlibat pada work task dalam proses produksi beton readymix. Durasi pemakaian alat ini lah yang nantinya digunakan dalam proses analisa produktivitas yang dihasilkan pada keseluruhan proses produksi beton readymix.

\section{G. Studi Kasus}

Pengambilan data dilakukan pada 3 lokasi batching plant yang berada di Gresik, Malang, dan Gempol. Karakteristik dari tiap lokasi batching plant sebagai berikut:

\section{Studi Kasus I}

Pada plant ini kapasitas pan pengaduk yang digunakan sebesar $3 \mathrm{~m}^{3}$, akan tetapi kapasitas $3 \mathrm{~m}^{3}$ tidak dapat digunakan sepenuhnya dalam proses pencampuran karena akan membuat beton yang berada didalamnya akan mudah tumpah. Maka pan hanya di isi maksimal 2,5 $\mathrm{m}^{3}$.
Dalam mengoperasikan pan pengaduk ini menggunakan tenaga listrik. Durasi proses produksi pada plant ini tergambarkan pada Gambar 1.

\section{Studi Kasus II}

Kapasitas truck mixer yang digunakan untuk proses pencampuran drymix ini adalah sebesar $6 \mathrm{~m}^{3}$, akan tetapi kapasitas $6 \mathrm{~m}^{3}$ tidak lah dapat digunakan sepenuhnya dalam proses pencampuran karena akan membuat beton yang berada didalamnya akan mudah tumpah saat perjalanan menuju lokasi . Maka truck mixer hanya di isi maksimal $5 \mathrm{~m}^{3}$. Dalam mengoperasikan mixer ini menggunakan bahan bakar dari solar untuk menggerakan motor yang terdapat di bagian belakang tempat duduk kemudi. Proses produksi pada plant ini tergambarkan pada Gambar 2.

\section{Studi Kasus III}

Kapasitas truck mixer yang digunakan untuk proses pencampuran drymix ini adalah sebesar $8 \mathrm{~m}^{3}$, akan tetapi kapasitas $8 \mathrm{~m}^{3}$ tidak dapat digunakan sepenuhnya dalam proses pencampuran karena akan membuat beton yang berada didalamnya akan mudah tumpah saat perjalanan menuju lokasi . Maka truck mixer hanya di isi maksimal 7 $\mathrm{m}^{3}$. Dalam mengoperasikan mixer ini menggunakan bahan bakar dari solar untuk menggerakan motor yang terdapat di bagian belakang tempat duduk kemudi. Proses produksi pada plant ini tergambarkan pada Gambar 3.

Tabel 2. Rekapitulasi Durasi Work task Produksi Beton Readymix Studi Kasus I

\begin{tabular}{|r|l|r|r|r|r|r|r|r|}
\hline \multirow{2}{*}{ NODE } & \multirow{2}{*}{ AKTIFITAS } & \multicolumn{7}{|c|}{ DURASI SIKLUS KE- (dtk) } \\
\cline { 2 - 9 } & & $\mathbf{1}$ & $\mathbf{2}$ & $\mathbf{3}$ & $\mathbf{4}$ & $\mathbf{5}$ & $\mathbf{6}$ & $\mathbf{7}$ \\
\hline 3 & Excavate & 10 & 8 & 6 & 7 & 8 & 6 & 9 \\
\hline 4 & Loader Travel & 40 & 37 & 25 & 32 & 28 & 28 & 27 \\
\hline 7 & Fill Hooper & 8 & 7 & 9 & 10 & 7 & 9 & 7 \\
\hline 8 & Loader Back & 45 & 42 & 32 & 34 & 35 & 24 & 28 \\
\hline 12 & Load Conveyor & 25 & 20 & 30 & 25 & 18 & 20 & \\
\hline 13 & Travel to Mixer & 33 & 23 & 39 & 39 & 30 & 43 & \\
\hline 17 & Dump Material & 14 & 16 & 19 & 14 & 24 & 16 & \\
\hline 18 & Mix & 30 & 31 & 45 & 43 & 33 & 40 & \\
\hline 21 & Fill Truck Mixer & 18 & 15 & 32 & 38 & 20 & 24 & \\
\hline 24 & Leave Batch & 5 & 5 & 5 & & & & \\
\hline
\end{tabular}




\begin{tabular}{|r|l|r|r|r|r|r|r|r|}
\hline \multirow{2}{*}{ NODE } & \multirow{2}{*}{ AKTIFITAS } & \multicolumn{7}{|c|}{ DURASI SIKLUS KE- (dtk) } \\
\cline { 2 - 9 } & & $\mathbf{1}$ & $\mathbf{2}$ & $\mathbf{3}$ & $\mathbf{4}$ & $\mathbf{5}$ & $\mathbf{6}$ & $\mathbf{7}$ \\
\hline 3 & Excavate & 10 & 8 & 10 & 15 & 10 & 6 & 5 \\
\hline 4 & Loader Travel & 45 & 46 & 34 & 34 & 44 & 42 & 41 \\
\hline 7 & Fill Hooper & 20 & 35 & 5 & 18 & 4 & 5 & 7 \\
\hline 8 & Loader Back & 46 & 45 & 54 & 35 & 39 & 36 & 29 \\
\hline 12 & Load Conveyor & 89 & 95 & 122 & & & & \\
\hline 13 & Travel to Mixer & 120 & 150 & 168 & & & & \\
\hline 17 & Dump Material & 100 & 114 & 121 & & & & \\
\hline 18 & Mix & 355 & 471 & 402 & & & & \\
\hline 24 & Leave Batch & 6 & 7 & 7 & & & & \\
\hline
\end{tabular}

Tabel 4. Rekapitulasi Durasi Work task Produksi Beton Readymix Studi Kasus III

\begin{tabular}{|c|c|c|c|c|c|c|c|c|c|c|c|c|c|c|c|c|}
\hline \multirow{2}{*}{ NODE } & \multirow{2}{*}{ AKTIFITAS } & \multicolumn{15}{|c|}{ DURASI SIKLUS KE- (dtk) } \\
\hline & & 1 & 2 & 3 & 4 & 5 & 6 & 7 & 8 & 9 & 10 & 11 & 12 & 13 & 14 & 15 \\
\hline 3 & Excavate & 7 & 10 & 6 & 6 & 6 & 6 & 15 & 6 & 3 & 4 & 4 & 6 & 6 & 4 & 6 \\
\hline 4 & Loader Travel & 22 & 19 & 18 & 27 & 20 & 19 & 19 & 11 & 28 & 46 & 15 & 15 & 26 & 16 & 35 \\
\hline 7 & Fill Hooper & 45 & 6 & 31 & 58 & 39 & 49 & 5 & 23 & 39 & 39 & 32 & 15 & 37 & 38 & 23 \\
\hline 8 & Loader Back & 44 & 16 & 16 & 26 & 22 & 48 & 29 & 30 & 24 & 17 & 22 & 25 & 31 & 30 & 35 \\
\hline 12 & Load Conveyor & 78 & 90 & 83 & & & & & & & & & & & & \\
\hline 13 & Travel to Mixer & 92 & 101 & 92 & & & & & & & & & & & & \\
\hline 17 & Dump Material & 46 & 48 & 43 & & & & & & & & & & & & \\
\hline 18 & Mix & 335 & 349 & 282 & & & & & & & & & & & & \\
\hline 24 & Leave Batch & 15 & 12 & 13 & & & & & & & & & & & & \\
\hline
\end{tabular}

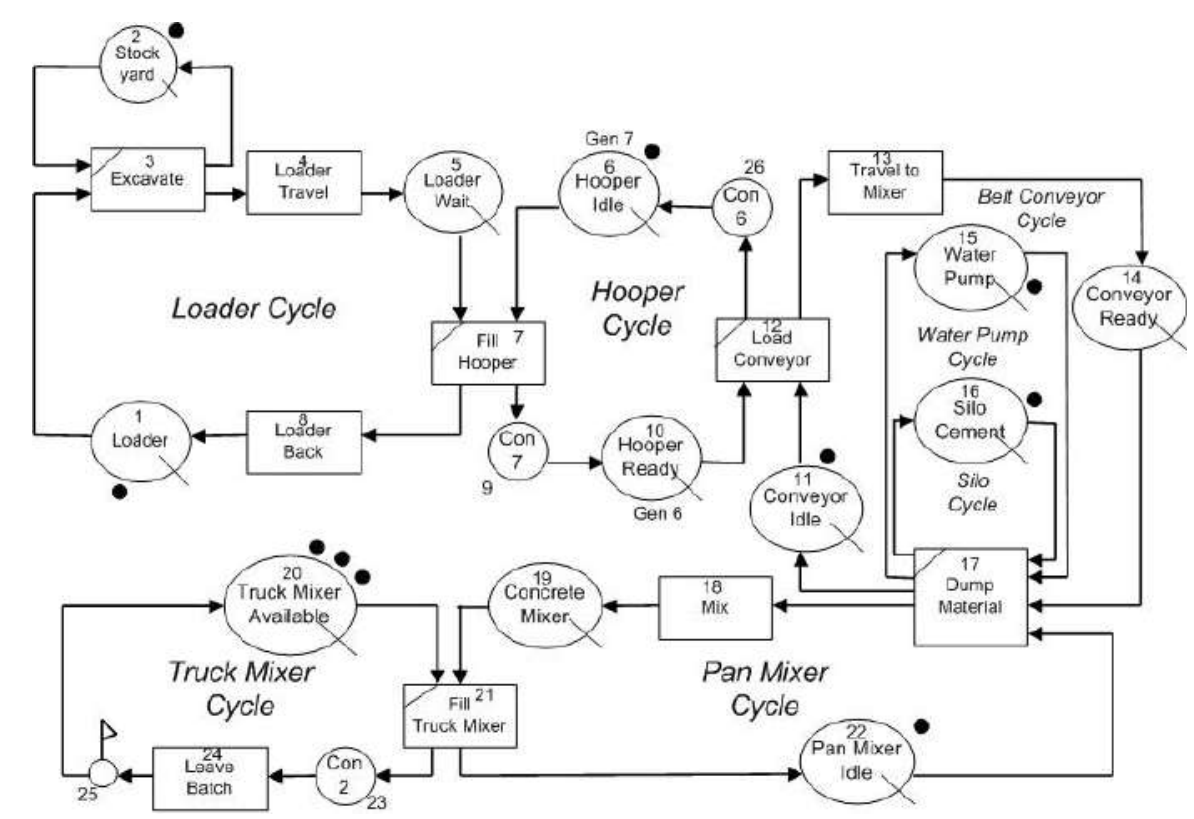

Gambar 1. Simulasi Produksi Plant PT. Varia Usaha Beton, Gresik 


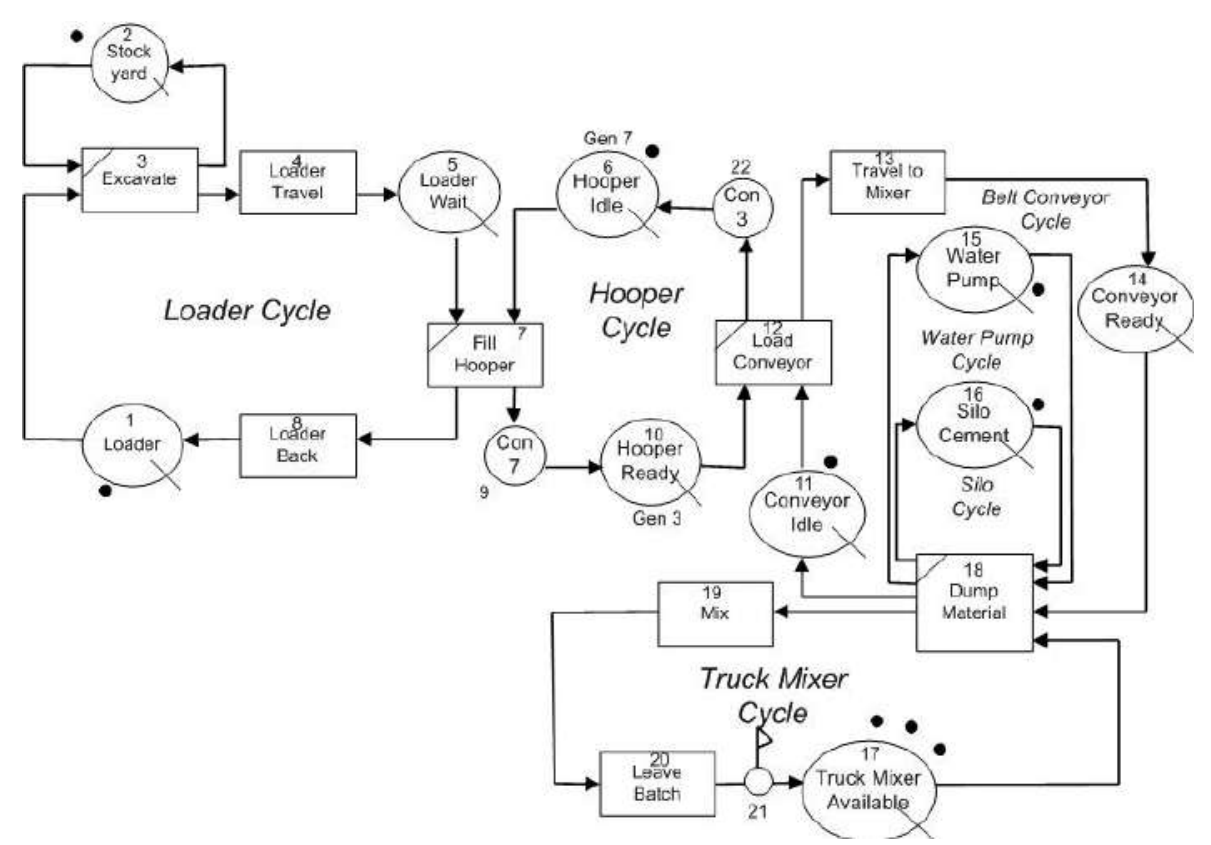

Gambar 2. Simulasi Produksi Plant PT. Surya Beton Indonesia, Malang

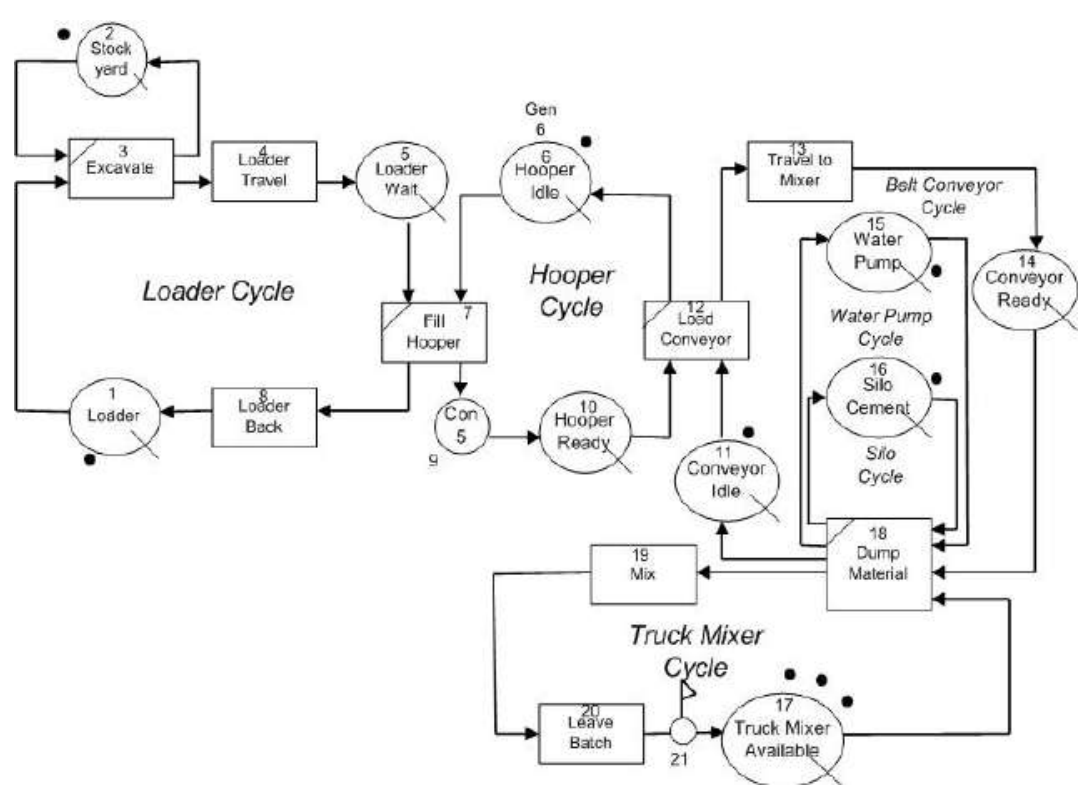

Gambar 3. Simulasi Produksi Plant PT. SCG Readymix Indonesia, Gempol

\section{ANAlisis}

Dalam penelitian ini terdapat satu lokasi studi kasus untuk wetmix dan dua lokasi studi kasus untuk drymix. Karakteristik dari ketiga batching plant tersebut pun berbeda antara satu dengan yang lain. Perbedaan masingmasing lokasi secara garis besar dapat digambarkan pada kapasitas hooper dan jenis batching plant. Analisis selanjutnya dapat dilihat sebagai berikut.

adapun Durasi yang digunakan dalam estimasi ini, merupakan hasil simulasi berdasarkan model yang telah disimulasikan dalam software WebCyclone. Selanjutnya estimasi produktivitas dilakukan dengan melihat durasi steady untuk memproduksi beton berdasarkan simulasi software WebCyclone.

\section{A. Analisis Produktivitas Studi Kasus I}

Pada proses simulasi ini, dilakukan proses simulasi sebanyak 1000 siklus agar didapat durasi work task yang optimal atau steady, sehingga apabila pada tiap siklus diproduksi beton sebanyak $5 \mathrm{~m} 3$, maka proses simulasi ini akan menghasilkan beton sebesar 5000 m3.Berdasarkan hasil pengamatan durasi pada beberapa siklus, dilakukan simulasi menggunakan software 
WebCyclone. Sehingga di dapat hasil simulasi pada Tabel 4 dan Gambar 4.

Tabel 4. Outcome Simulasi Studi Kasus I

\begin{tabular}{|c|c|c|c|c|c|c|}
\hline \multicolumn{7}{|c|}{ CONCFUIT WTISAX PROCISS } \\
\hline & & \multicolumn{4}{|c|}{ ProvUCTVIIY LTORSUTION } \\
\hline \multirow{2}{*}{\multicolumn{3}{|c|}{ 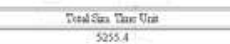 }} & Cykikl & \multirow{2}{*}{\multicolumn{3}{|c|}{ 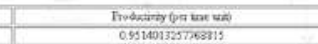 }} \\
\hline & & & $\frac{1060}{1000}$ & & & \\
\hline \multicolumn{7}{|c|}{ COHCСRTT WETMCX PRCCTSS } \\
\hline \multicolumn{7}{|c|}{ 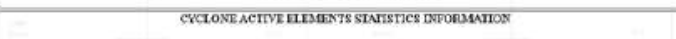 } \\
\hline tham $3 \mathrm{3pt}$ & [Bin. & Kowe & Locolit Cuset & howas Evans & Kemesearsos & Unomin Drain \\
\hline cosisit & 3 & EXCNVRIE & 250 & 32 & 06 & 08 \\
\hline Sormuat & 4 & TKAJPLE & 2309 & 25 & 07 & 04 \\
\hline combs & $\frac{7}{7}$ & FII MOOFE & 2398 & 21 & 02 & 01 \\
\hline Horesut & $\frac{1}{3}$ & TENEL ACC: & 2338 & 96 & 12 & 00 \\
\hline 000101 & 112 & $10 \mathrm{~N}$ COSAVIVOT & 3001 & 20 & 05 & 6 \\
\hline POOBAAL & 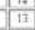 & TRAV TO NDSB & 2001 & 0.6 & os & 04 \\
\hline CONBS & 17 & 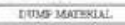 & 2000 & 23 & 64 & 02 \\
\hline MORMat & 118 & 100 & $+\infty, 0$ & 0.6 & 01 & 04 \\
\hline cones & 21 & FIIIUUCZZCKR & 2000 & 24 & 07 & 63 \\
\hline HOTHAL & 34 & एस. & $x 00$ & 01 & 0,1 & 01 \\
\hline
\end{tabular}

Product vity Chart of CONCRETE WETMIX PROCESS with 1000 cycles

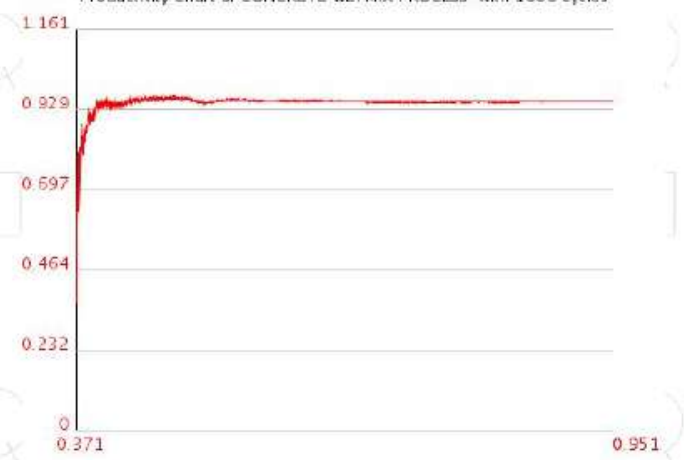

Gambar 4. Grafik Produktivitas Studi Kasus I

Setelah dilakukan proses simulasi, didapatkan beberapa informasi dari proses produksi beton batching plant dengan 1000 kali siklus simulasi pada metode pencampuran wetmix ini. Diantaranya untuk mencapai siklus produksi ke 1000 dibutuhkan waktu produksi sebesar 5255,4 menit. Selain itu diketahui pula bahwa produktivitas batching plant ini sebesar $0,95 \mathrm{~m} 3 /$ menit atau apabila di konversi dalam satuan jam, plant ini mampu memproduksi beton sebesar $57 \mathrm{~m} 3 /$ jam

\section{B. Analisis Produktivitas Studi Kasus II}

Pada proses simulasi ini, dilakukan proses simulasi sebanyak 1000 siklus agar didapat durasi work task yang optimal atau steady, sehingga apabila pada tiap siklus diproduksi beton sebanyak $5 \mathrm{~m} 3$, maka proses simulasi ini akan menghasilkan beton sebesar 5000 m3.Berdasarkan hasil pengamatan durasi pada beberapa siklus, dilakukan simulasi menggunakan software WebCyclone. Sehingga di dapat hasil simulasi pada Tabel 5 dan Gambar 5.
Tabel 5. Outcome Simulasi Studi Kasus II

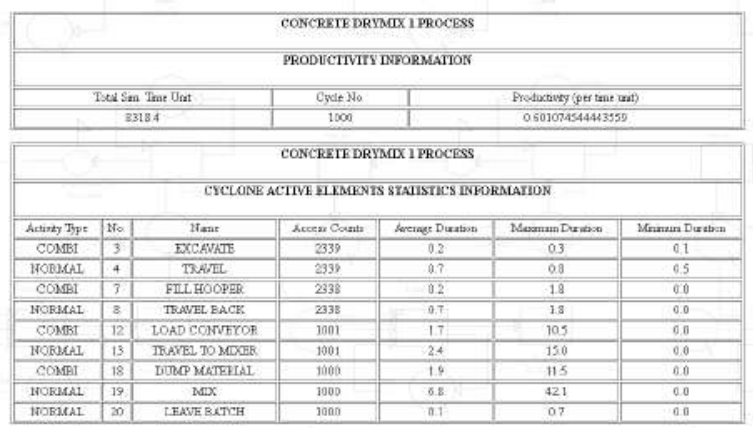

Productivity Chart of CONCRETE DRYMIX 1 PROCES with 1000 cycles

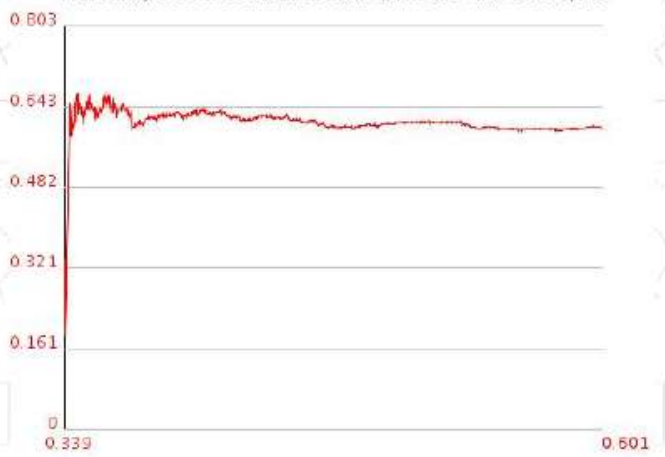

Gambar 5. Grafik Produktivitas Studi Kasus II

Setelah dilakukan proses simulasi, didapatkan beberapa informasi dari proses produksi beton batching plant dengan 1000 kali siklus simulasi pada metode pencampuran wetmix ini. Diantaranya untuk mencapai siklus produksi ke 1000 dibutuhkan waktu produksi sebesar 8318,4 menit. Selain itu diketahui pula bahwa produktivitas batching plant ini sebesar $0,60 \mathrm{~m} 3 / \mathrm{menit}$ atau apabila di konversi dalam satuan jam, plant ini mampu memproduksi beton sebesar $36 \mathrm{~m} 3 / \mathrm{jam}$

\section{Analisis Produktivitas Studi Kasus III}

Pada proses simulasi ini, dilakukan proses simulasi sebanyak 1000 siklus agar didapat durasi work task yang optimal atau steady, sehingga apabila pada tiap siklus diproduksi beton sebanyak $6 \mathrm{~m} 3$, maka proses simulasi ini akan menghasilkan beton sebesar 6000 m3.Berdasarkan hasil pengamatan durasi pada beberapa siklus, dilakukan simulasi menggunakan software WebCyclone. Sehingga di dapat hasil simulasi pada Tabel 6 dan Gambar 6. 
Tabel 6. Outcome Simulasi Studi Kasus III
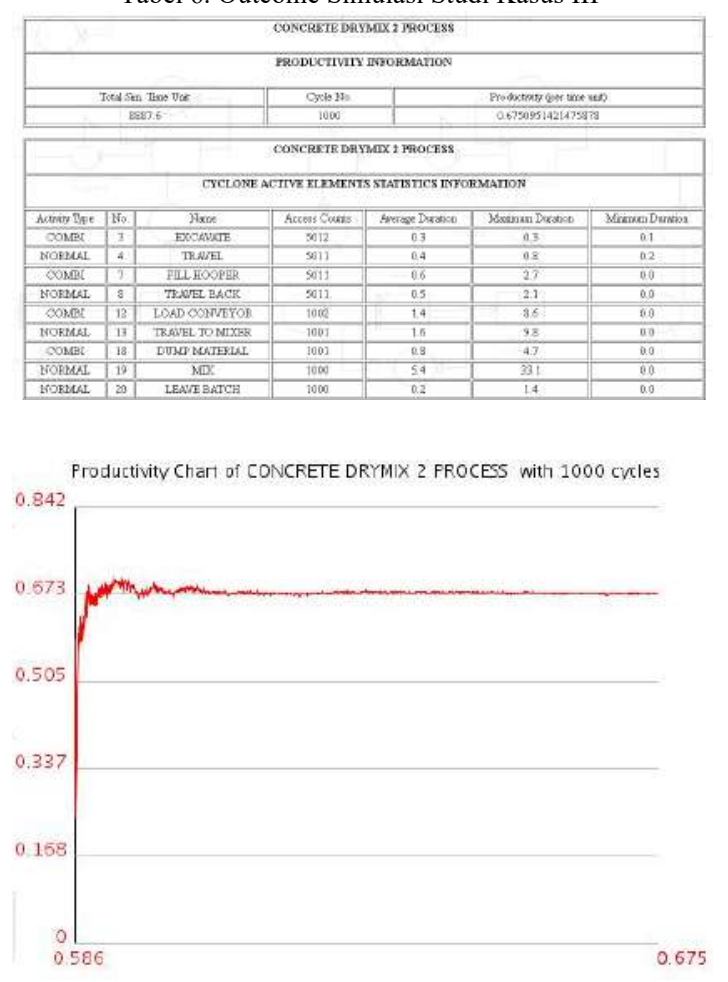

Gambar 6. Grafik Produktivitas Studi Kasus III

Setelah dilakukan proses simulasi, didapatkan beberapa informasi dari proses produksi beton batching plant dengan 1000 kali siklus simulasi pada metode pencampuran wetmix ini. Diantaranya untuk mencapai siklus produksi ke 1000 dibutuhkan waktu produksi sebesar 8887,6 menit. Selain itu diketahui pula bahwa produktivitas batching plant ini sebesar $0,675 \mathrm{~m} 3 /$ menit atau apabila di konversi dalam satuan jam, plant ini mampu memproduksi beton sebesar $41 \mathrm{~m} 3 / \mathrm{jam}$

\section{Perbandingan}

Berdasarkan hasil simulasi pada seluruh lokasi batching plant, diketahui nilai perbandingan produktivitas sebagai berikut:

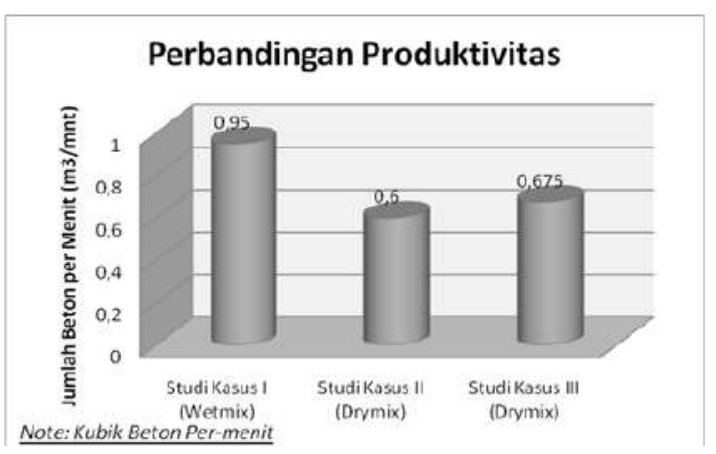

Gambar 7. Grafik Perbandingan Produktivitas Batching plant

Hasil ini menunjukan produktivitas beton yang di produksi pada batchingplant tipe wetmix dapat memberikan produktivitas yang cukup tinggi dibandingkan tipe drymix. Berdasarkan pengamatan, penyebab lamanya proses produksi adalah karena durasi pencampuran yang berbeda cukup signifikan. Durasi mixing pada wetmix hanya membutuhkan durasi kurang dari 1 menit per satu kali campuran, yang jika ingin memproduksi beton dengan memenuhi truck mixer akan membutuhkan waktu kurang lebih 2 menit, sedangkan pada drymix membutuhkan waktu mixing lebih dari 5 menit untuk produksi 1 truck mixer.

\section{E. Analisis Potensi Perbaikan}

Berdasarkan hasil analisa produktivitas di atas dapat disimpulkan bahwa batchingplant wetmix memiliki produktivitas yang tinggi dibanding drymix. Hasil pengamatan lapangan dan hasil analisa simulasi menunjukkan hal yang hampir sama, yaitu penggunaan loader sebagai alat angkut agregat memiliki peran yang sangat vital pada proses produksi. Hal ini dapat diamati berdasarkan rekap waktu tunggu yang bernilai nol, sehingga menandakan loader selalu bekerja terus menerus ketika proses produksi berlangsung seperti yang ditunjukan pada Tabel 7.

Tabel 7. Perbandingan Waktu Tunggu Loader dan Concrete Mixer

\begin{tabular}{|r|l|r|r|r|}
\hline \multirow{2}{*}{ NO } & \multirow{2}{*}{ RESOURCE } & \multicolumn{3}{|c|}{ BATCHINGPLANT } \\
\cline { 3 - 5 } & & \multicolumn{1}{c|}{ I } & \multicolumn{1}{c|}{ II } & III \\
\cline { 3 - 5 } & & WETMIX & DRYMIX & DRYMIX \\
\hline 1 & Loader Wait & 0 & 0 & 0 \\
\hline 2 & Concrete Mixer & 1.3 & 16.1 & 20.2 \\
\hline
\end{tabular}

Namun dengan kesibukan loader yang sangat tinggi, ternyata tidak di imbangi dengan kecepatan produksi pada alat pencampur beton. Pada batchingplant I tampak bahwa alat pengaduk beton (pan mixer) cukup singkat dibandingkan batching plant tipe drymix (Tabel 7). Waktu tunggu yang singkat menandakan alat tersebut memiliki produktivitas yang tinggi jika dibandingkan yang memiliki waktu tunggu yang besar.

Perbaikan yang dapat dilakukan tentunya perlu menganalisis 2 pekerjaan utama tersebut, yaitu berfokus pada proses pengisian agregat ke dalam hooper yang melibatkan loader sebagai alat utama dan proses pencampuran yang dilakukan pan mixer atau truck mixer yang memiliki perbedaan siknifikan dalam pemrosesan material. Pada tabel IV.20 ditunjukan waktu siklus masing-masing loader di tiap batchingplant. Dapat dilihat bahwa waktu siklus pada batchingplant I cukup cepat dibandingkan batchingplant II dan III. Berdasarkan pengamatan, sebab lamanya siklus kerja loader pada batchingplant II di karenakan loader mengambil agregat ke stock yard cukup jauh menuju hooper sehingga travel time loader cukup lama. Sedangkan pada batchingplant III permasalahan yang dihadapi oleh loader adalah kapasitas hooper yang cukup kecil, sehingga proses fill hooper memakan waktu lama. Berbeda dengan batchingplant 1 yang cukup singkat karena lokasi stock 
yard cukup dekat dan hooper yang cukup besar sehingga pekerjaan loader dapat lebih mudah.

Tabel 8. Perbandingan Waktu Rata-rata Siklus Kerja Loader (menit)

\begin{tabular}{|c|c|c|c|c|}
\hline \multirow{3}{*}{ NO } & \multirow{3}{*}{ TASK } & \multicolumn{3}{|c|}{ BATCHINGPLANT } \\
\hline & & I & II & III \\
\hline & & WETMIX & DRYMIX & DRYMIX \\
\hline 1 & EXCAVATE & 0.2 & 0.2 & 0.3 \\
\hline 2 & TRAVEL & 0.5 & 0.7 & 0.4 \\
\hline 3 & FILL HOOPER & 0.1 & 0.2 & 0.6 \\
\hline 4 & TRAVEL BACK & 0.6 & 0.7 & 0.5 \\
\hline & TOTAL SIKLUS KERJA & 1.40 & 1.80 & 1.80 \\
\hline
\end{tabular}

Jika pada batchingplant II dan III dilakukan desain layout penempatan stock yard dan hooper seperti batchingplant 1, maka produktivitas dari kedua batchingplant tersebut dapat dilihat seperti tabel IV.21 dan IV.22 berikut.

Tabel 9. Output Simulasi Perbaikan Studi Kasus II

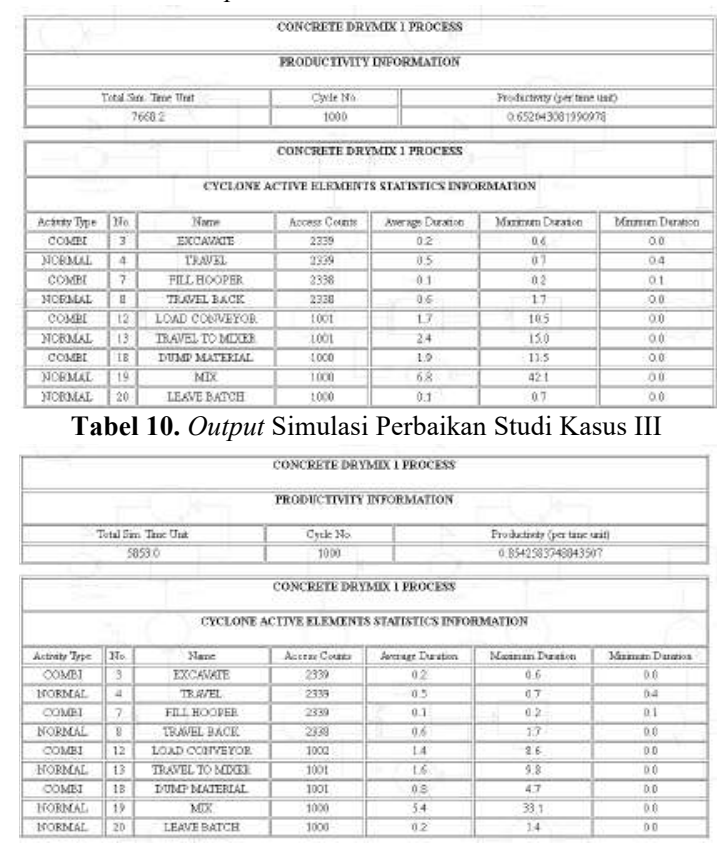

Jika loader pada batchingplant II dan III bekerja seperti halnya kondisi batchingplant I, maka dapat dilihat terjadi kenaikan produktivitas seperti hasil simulasi, yaitu produktivitas meningkat menjadi $0,65 \mathrm{~m} 3 /$ menit dari yang awalnya $0,60 \mathrm{~m} 3 /$ menit seperti grafik yang ditunjukan pada gambar IV.17. Sementara pada batchingplant III akan mengalami peningkatan produktivitas dari $0,675 \mathrm{~m} 3 /$ menit menjadi 0,85 m3/menit seperti yang ditunjukan pada Gambar 8 .

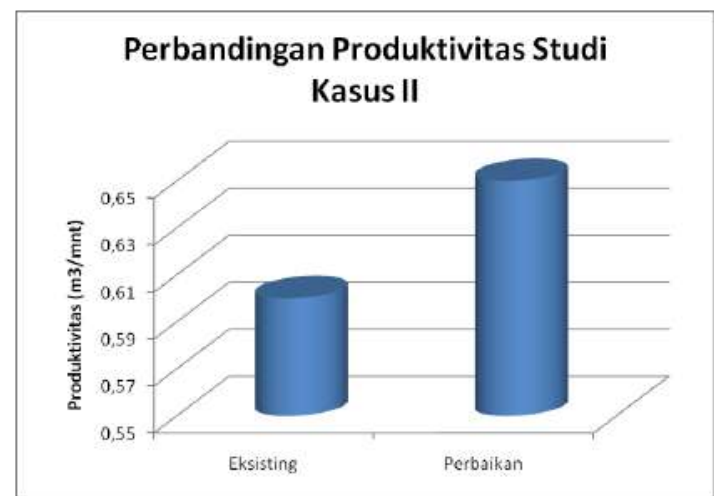

Gambar 8. Grafik Perbandingan Produktivitas Studi Kasus II

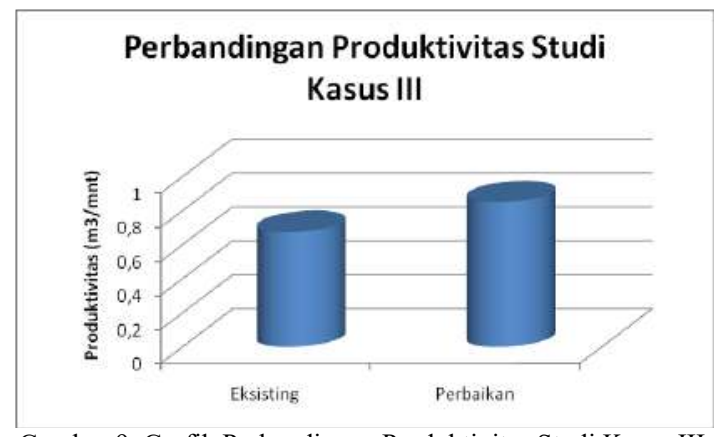

Gambar 9. Grafik Perbandingan Produktivitas Studi Kasus III

Dari hasil simulasi tersebut dapat ditarik sebuah kesimpulan, bahwa peran loader dalam bekerja dapat mempengaruhi produktivitas keseluruhan batchingplant. Hal ini wajar dikarenakan proses produksi tidak dapat dilakukan jika agregat kasar dan halus tidak dimasukan terlebih dahulu kedalam hooper. Maka peningkatan produktivitas juga semakin meningkat jika ketersedian agregat didalam hooper dapat di supply dengan baik. Dalam hal ini didukung oleh tata letak stock yard yang dekat dan kapasitas hooper yang besar agar loader dapat bekerja secara efektif.

Akan tetapi, walaupun produktivitas batchingplant II dan III meningkat, peningkatan tersebut masih dibawah produktivitas batchingplant I yang menggunakan tipe wetmix. Berdasarkan hasil pengamatan, kecepatan mixing sangat mempengaruhi kecepatan produksi tersebut. Nampak pada tabel IV.23 berikut kecepatan mixer per $\mathrm{m} 3$ pada pan mixer ternyata menunjukan waktu yang cukup singkat, yaitu sebesar 0,24 menit atau setara 14 detik.

Tabel 11. Perbandingan Rata-rata Mixing per $\mathrm{m} 3$

\begin{tabular}{|r|l|r|r|r|l|}
\hline \multirow{2}{*}{ NO } & \multirow{2}{*}{ TASK } & \multicolumn{3}{|c|}{ BATCHINGPLANT } & \multirow{2}{*}{ SATUAN } \\
\cline { 3 - 5 } & & \multicolumn{1}{|c|}{ I } & \multicolumn{1}{c|}{ II } & III & \multirow{2}{*}{ SATUA } \\
\cline { 3 - 5 } & & WETMIX & DRYMIX & DRYMIX & \\
\hline 1 & MIX & 0.6 & 6.8 & 5.4 & $\mathrm{~min}$ \\
\hline 2 & PRODUCTION per Cycle & 2.5 & 5 & 7 & $\mathrm{~m} 3$ \\
\hline \multicolumn{2}{|c|}{ TOTAL SIKLUS MIX/m3 } & $\mathbf{0 . 2 4}$ & $\mathbf{1 . 3 6}$ & $\mathbf{0 . 7 7}$ & $\mathrm{min} / \mathrm{m3}$ \\
\hline
\end{tabular}

Sedangkan pada pencampuran pada metode drymix atau menggunakan truck mixer dalam proses pencampuran 
membutuhkan waktu yang lebih lama yaitu berkisar 0,77 sampai 1,36 menit per $\mathrm{m} 3$ atau membutuhkan waktu sekitar 46,2 detik hingga 81 detik per $m 3$ beton. Sehingga dapat disimpulkan bahwa pencampuran drymix membutuhkan waktu yang lama dalam melakukan proses produksi beton readymix berdasarkan hasil pengambilan data di lapangan.

\section{KESIMPULAN}

Berdasarkan analsisis produktivitas dua jenis metode produksi beton yang telah diteliti, diperoleh kesimpulan sebagai berikut:

- Berdasarkan hasil penelitian dan analisis yang dilakukan dapat diketahui bahwa produktivitas batchingplant tipe wetmix memiliki produktivitas yang lebih tinggi di bandingkan tipe drymix

- Proses yang menghambat kecepatan produksi beton readymix tipe drymix dikarenakan proses mixing yang lebih lama, yaitu diatas 5 menit, sedangkan untuk volume produksi yang sama, tipe wetmix membutuhkan waktu sekitar 2 menit. Selain itu tata letak stock yard yang terlalu jauh dan ukuran hooper yang terlalu kecil juga mempengaruhi produktivitas loader untuk melakukan pengisian agregat untuk proses produksi beton.

- Perbaikan yang dapat dilakukan agar dapat meningkatkan produktivitas batchingplant adalah melakukan pencampuran ke dalam pan mixer yang dimiliki oleh tipe wetmix, selain itu penempatan stock yard untuk agregat kasar dan agregat halus diupayakan agar lebih dekat dengan hooper agar travel time loader dapat lebih cepat, selain itu kapasitas hooper yang besar dapat mempermudah proses dumping yang dilakukan loader agar produktivitas dapat lebih meningkat.

\section{DAFTAR PUSTAKa}

[1] Abduh, Muhamad. 2015, "Bahan Kuliah SI-5151 Produktivitas Konstruksi”, Tidak Dipublikasikan, Institut Teknologi Bandung.

[2] Halpin, Daniel W, Riggs, Leland S,1992,"Planning and Analysis of Construction Operations", Indiana: Jhon Wiley \& Sons, Inc.

[3] Octavia,D. (2014): Pemilihan Metoda Kerja Pengecoran Beton yang Rendah Emisi dengan Simulasi, Tesis Manajemen Rekayasa Konstruksi, Institut Teknologi Bandung.

[4] Oglesby, Clarkson H, et al., 1989, "Productivity Improvement in Construction”, New York: McGraw-Hill. 